\title{
Role of prion protein glycosylation in replication of human prions by protein misfolding cyclic amplification
}

\author{
Manuel V. Camacho ${ }^{1} \cdot$ Glenn Telling $^{2} \cdot$ Qingzhong Kong $^{1,3} \cdot$ Pierluigi Gambetti $^{1} \cdot$ Silvio Notari $^{1}$
}

Received: 18 February 2019 / Revised: 11 May 2019 / Accepted: 28 May 2019 / Published online: 27 June 2019

(c) The Author(s), under exclusive licence to United States and Canadian Academy of Pathology 2019

\begin{abstract}
Prion diseases are transmissible neurological disorders associated with the presence of abnormal, disease-related prion protein $\left(\operatorname{PrP}^{\mathrm{D}}\right)$. The detection of $\operatorname{PrP}^{\mathrm{D}}$ in the brain is the only definitive diagnostic evidence of prion disease and its identification in body fluids and peripheral tissues are valuable for pre-mortem diagnosis. Protein misfolding cyclic amplification (PMCA) is a technique able to detect minute amount of $\mathrm{PrP}^{\mathrm{D}}$ and is based on the conversion of normal or cellular $\operatorname{PrP}\left(\operatorname{PrP}^{\mathrm{C}}\right)$ to newly formed $\operatorname{PrP}^{\mathrm{D}}$, sustained by a self-templating mechanism. Several animal prions have been efficiently amplified by PMCA, but limited results have been obtained with human prions with the exception of variantCreutzfeldt-Jakob-disease (vCJD). Since the total or partial absence of glycans on $\mathrm{PrP}^{\mathrm{C}}$ has been shown to affect PMCA efficiency in animal prion studies, we attempted to enhance the amplification of four major sporadic-CJD (sCJD) subtypes (MM1, MM2, VV1, and VV2) and vCJD by single round PMCA using partially or totally unglycosylated $\operatorname{PrP}^{\mathrm{C}}$ as substrates. The amplification efficiency of all tested sCJD subtypes underwent a strong increase, inversely correlated to the degree of $\mathrm{PrP}^{\mathrm{C}}$ glycosylation and directly related to the matching of the PrP polymorphic $129 \mathrm{M} / \mathrm{V}$ genotype between seed and substrate. This effect was particularly significant in SCJDMM2 and sCJDVV2 allowing the detection of PK-resistant $\operatorname{PrP}^{\mathrm{D}}$ $\left(\right.$ resPrP $\left.P^{\mathrm{D}}\right)$ in sCJDMM2 and sCJDVV2 brains at dilutions of $6 \times 10^{7}$ and $3 \times 10^{6}$. vCJD, at variance with the tested sCJD subtypes, showed the best amplification with partially deglycosylated $\operatorname{PrP}^{\mathrm{C}}$ substrate reaching a resPrP $\mathrm{P}^{\mathrm{D}}$ detectability at up to $3 \times 10^{16}$ brain dilution. The differential effect of substrate $\operatorname{PrP}^{\mathrm{C}}$ glycosylations suggests subtype-dependent $\operatorname{PrP}^{\mathrm{C}}-\mathrm{PrP}^{\mathrm{D}}$ interactions, strongly affected by the $\operatorname{PrP}^{\mathrm{C}}$ glycans. The enhanced PMCA prion amplification efficiency achieved with unglycosylated $\operatorname{PrP}^{\mathrm{C}}$ substrates may allow for the developing of a sensitive, non-invasive, diagnostic test for the different CJD subtypes based on body fluids or easily-accessible-peripheral tissues.
\end{abstract}

\section{Introduction}

Human prion diseases are characterized by a variety of disease phenotype often exhibiting very different clinical

Supplementary information The online version of this article (https:// doi.org/10.1038/s41374-019-0282-1) contains supplementary material, which is available to authorized users.

Silvio Notari

silvio.notari@gmail.com

1 Department of Pathology, Case Western Reserve University, Cleveland, $\mathrm{OH}$, USA

2 Prion Research Center, Department of Microbiology, Immunology and Pathology, Colorado State University, Fort Collins, CO, USA

3 Department of Neurology, Case Western Reserve University, Cleveland, $\mathrm{OH}$, USA presentations and disease durations [1-5]. Sporadic Creutzfeldt-Jakob disease (sCJD), which account for nearly 90\% of all human prion diseases, displays at least five distinct subtypes associated with different disease phenotypes, and a number of mixed phenotypes [6], which may differ widely not only concerning clinical presentation but also disease duration. The early identification of these subtypes may become increasingly important since future treatments of human prion diseases are likely to be selective as for type and subtype of prion disease [7, 8].

Recently, great progress has been made on the diagnosis of prion disease by the testing of body fluids (blood and urine) or peripheral tissues (olfactory mucosa and skin) based on real time-quaking induced conversion (RT-QuIC) [9-11] and other methods that rely on advanced prion enrichment approaches [12-15]. However, none of these tests can identify type or subtype of sCJD on individual patients, which currently can be achieved only by brain tissue examination $[4,16]$. 
Protein misfolding cyclic amplification (PMCA), based on the in vitro conversion of normal or cellular $\operatorname{PrP}\left(\operatorname{PrP}^{C}\right)$ to $\operatorname{PrP}^{\mathrm{D}}$, sustained by a self-templating mechanism [17] has shown an extraordinary competence to detect and faithfully replicate $\mathrm{PrP}^{\mathrm{D}}$ from animal scrapie, capable of detecting a single molecule of $\operatorname{PrP}^{\mathrm{D}}[18,19]$. However, amplification of $\mathrm{PrP}^{\mathrm{D}}$ from human prion patients has been difficult [20-22]. Notable exceptions are represented by variant CJD (vCJD), a form of prion disease acquired from consumption of prion contaminated bovine meat [23] and, to a lesser extent, iatrogenic CJD, another type of acquired CJD related to medical or surgical interventions; in both these conditions $\operatorname{PrP}^{\mathrm{D}}$ has been shown to amplify with high efficiency [22, 24, 25].

The achievement of high amplification efficiency by PMCA in body fluids or peripheral tissues from sCJD patients will likely allow for the accurate, non-invasive diagnosis of sCJD subtype early in the course, which will help plan the management and hopefully the future treatment of these patients.

Since several investigators reports have shown that glycan modification of mouse and hamster $\operatorname{PrP}^{\mathrm{C}}$, may affect PMCA efficiency [26-30], we tested substrates with glycan modified human $\mathrm{PrP}^{\mathrm{C}}$, as a preliminary attempt to improve the efficiency of PMCA of $\mathrm{sCJD} \mathrm{PrP} \mathrm{P}^{\mathrm{D}}$. For this purpose, we used a transgenic ( $\mathrm{Tg}$ ) mouse line expressing glycanfree human $\mathrm{PrP}^{\mathrm{C}}-129 \mathrm{M}$, generated in our lab, and $\mathrm{Tg}$ mouse lines expressing human $\operatorname{PrP}^{\mathrm{C}}-129 \mathrm{M}$ and $-129 \mathrm{~V}$, in conjunction with partial deglycosylation by PNGase $F$ treatment in non-denaturing conditions. Our results showed a significant increase of PMCA amplification of sCJD and vCJD $\operatorname{PrP}^{\mathrm{D}}$ strains when partially or totally deglycosylated human $\operatorname{PrP}^{\mathrm{C}}$ as a substrate was used.

\section{Materials and methods}

\section{Tissue samples}

Frontal cortex from two cases each with sCJDMM1, sCJDMM2, sCJDVV1, and sCJDVV2 along with one case with vCJD were obtained from the National Prion Disease Pathology Surveillance Center (NPDPSC) of Case Western Reserve University, Cleveland, $\mathrm{OH}$. Brain homogenates $(\mathrm{BH}), 10 \% \mathrm{w} / \mathrm{v}$, were prepared on ice in conversion buffer (Dulbecco's phosphate-buffered saline $1 \times, 150 \mathrm{mM} \mathrm{NaCl}$, $1 \%$ Triton $\mathrm{X}-100,5 \mathrm{mM}$ EDTA, $0.05 \%$ digitonin, $1 \times$ protease inhibitor cocktail) with a cell disrupter Mini-beadbeater (BioSpec). Partially deglycosylated human $\operatorname{PrP}^{\mathrm{C}}$ substrates were obtained by treating $\mathrm{BH}$ from $\mathrm{Tg}(\mathrm{HuPrPM})$ and $\mathrm{Tg}$ (HuPrPV) with $3200 \mathrm{U} / \mathrm{ml}$ of PNGase F in non-denaturing conditions for $1 \mathrm{~h}$ in a rotor at $37^{\circ} \mathrm{C}$. PNGase was not inactivated or removed from the substrates, as these treatments strongly affect the substrate efficiency in PMCA.

\section{Animals}

Three transgenic ( $\mathrm{Tg}$ ) mouse lines expressing human prion protein (PrP) were used. $\operatorname{Tg}(\mathrm{HuPrPM})$ and $\mathrm{Tg}(\mathrm{HuPrPV})$ expressed normal human $\operatorname{PrP}\left(\mathrm{PrP}^{\mathrm{C}}\right)$. TgNN6h line, generated in the Kong laboratory, expressed glycan-free human PrP-129M (HuPrPMGlyKO) at $0.6 \times$ the normal level (measured against wild type FVB mice) [21]. TgNN6h was generated by replacing the two asparagine residues for $(\mathrm{N})$ linked glycosylation at residues 181 and 197 with glutamine.

\section{Protein misfolding cyclic amplification (PMCA)}

PMCA was performed as previously described with minor modifications [17]. The $\mathrm{BH}$ from $\mathrm{Tg}(\mathrm{HuPrPM}), \mathrm{Tg}$ (HuPrPM)-PNGase treated, Tg(HuPrPV), Tg(huPrPV)PNGase treated and TgNN6h were mixed in a 9:1 ratio with $\mathrm{BH}$ from the different sporadic CJD (sCJD) or variant CJD (vCJD) in the presence of $0.05 \%$ digitonin detergent (Sigma-Aldrich). The obtained $\mathrm{BH} 10 \%$ was serially diluted $1: 10\left(10^{-2}-10^{-N}, N\right.$ depending on the subtype) with the respective substrates. Unseeded substrates were also processed by PMCA as negative control (in quadruplicate for each of the $N$ PMCA experiments performed for seeded substrates, as specified). $N$ PMCA experiments were performed for each subtype-substrate group as specified, testing 2 cases for every subtypes, with the exception of vCJD and MM2 with $129 \mathrm{~V}+$ PNGase substrate, where single cases were analyzed. A single round of PMCA was carried out in a programmable sonicator (Qsonica Q500; Qsonica LLC, Newtown, CT) for 96 cycles. Each cycle consisted of $30 \mathrm{~s}$ of sonication and $29.5 \mathrm{~min}$ of incubation at $37^{\circ} \mathrm{C}$. One Teflon bead of $2.38 \mathrm{~mm}$ (McMaster-Carr, Los Angeles, CA) was added to each tube. The sonicator was operated at an amplitude optimized for each substrate. When the partially deglycosylated $\operatorname{PrP}^{\mathrm{C}}$ substrates were used, an amplitude of 24 was selected. For fully glycosylated and fully unglycosylated $\operatorname{PrP}^{\mathrm{C}}$ substrates, amplitudes of 28 and 26 were used, respectively.

\section{Western blot}

Aliquots of serially diluted $\mathrm{BH}$, before and after PMCA treatment, were treated for $1 \mathrm{~h}$ at $40{ }^{\circ} \mathrm{C}$ with proteinase $\mathrm{K}$ (PK) (Roche Diagnostics) at the concentration of $200 \mu \mathrm{g} /$ $\mathrm{ml}$. At the end of PK digestion sample buffer $2 \times$ (Laemmli sample buffer, BioRad) was added 1:2 and the samples boiled for $10 \mathrm{~min}$. Denatured samples were mixed 1:5 with pre-chilled methanol, vortexed and incubated at $-20{ }^{\circ} \mathrm{C}$ for at least $2 \mathrm{~h}$ before centrifugation at $16,000 \times g$ for 30 min at $4{ }^{\circ} \mathrm{C}$. The pellets were resuspended in sample buffer and boiled for $10 \mathrm{~min}$ before loading. Protein samples were separated with Tris-glycine SDS-PAGE in $15 \%$ Criterion Tris- $\mathrm{HCl}$ polyacrylamide precast gels (Bio-Rad 
Laboratories, Hercules, CA, USA) and transferred to Immobilon-P PVDF transfer membrane (EMD-Millipore, Billerica, MA, USA) for $2 \mathrm{~h}$ at $60 \mathrm{~V}$, blocked with $5 \%$ nonfat dry milk in $0.1 \%$ Tween, $20 \mathrm{mM}$ Tris-buffered saline, $\mathrm{pH} 7.5$, and probed with the $3 \mathrm{~F} 4$ antibody to $\operatorname{PrP}$. The immunoreactivity was visualized by enhanced chemiluminescence (Pierce ECL 2, Fisher Scientific, Hampton, NH, USA) on Kodak BioMax Light films (Eastman Kodak Co., Rochester, NY, USA).

Maximum amplification of PK-resistant disease-associated PrP $\left(\right.$ resPrP $\left.{ }^{\mathrm{D}}\right)$ detected after PMCA treatment was determined by limit dilution and expressed as the highest dilution of the seed allowing detection of resPrP $\mathrm{P}^{\mathrm{D}}$ (detection limit). Amplification efficiency was expressed as the ratio of resPrP $\mathrm{P}^{\mathrm{D}}$ concentrations, quantified by densitometry, detected in PMCA-treated vs PMCA-untreated samples, multiplied by the increase of brain dilution detectability $\left[\left(\mathrm{resPrP}^{\mathrm{D}}\right.\right.$ $\left.\mathrm{PMCA}+/ \mathrm{resPrP} \mathrm{D}^{\mathrm{D}} \mathrm{PMCA}-\right) \times$ limit dilution increase]. Densitometry was performed on the scanned WBs images by UN-SCAN-IT software (Silk Scientific).

\section{PrPD quantification}

Concentration of $\mathrm{vCJD}-\mathrm{res} \mathrm{PrP}^{\mathrm{D}}$ was obtained comparing, by western blotting, brain homogenate aliquots with serially diluted recombinant PrP (recPrP) 23-231. Densitometry was performed on the scanned WBs images by UN-SCAN-IT software and resPrP $\mathrm{P}^{\mathrm{D}}$ concentration calculated by extrapolation of the recPrP calibration curve.

\section{Statistical analysis}

Statistical analyses were performed with analysis of variance (one-way ANOVA) of amplifications obtained with the different substrates for either each or all CJD subtypes, as specified, followed by Tukey's multiple comparison test. For the comparison of subtype-specific PMCA efficiency, one-way ANOVA was also calculated on the groups formed by the amplifications, with the same substrate, of the different subtypes, followed by Tukey's test.

\section{Results}

\section{Quantification of PrP ${ }^{C}$ in the different transgenic mice lines}

Analysis of brain $\operatorname{PrP}^{\mathrm{C}}$ concentration in the three $\mathrm{Tg}$ mice lines showed a virtual equivalence between $\operatorname{Tg}(\mathrm{HuPrPV})$ and TgNN6h (with glycan-free human PrP-129M), 1.1 $\times$ and $1 \times$ respectively, and a $4.1 \times$ higher $\operatorname{PrP}^{\mathrm{C}}$ concentration in $\mathrm{Tg}$ (HuPrPM) (Supplementary Fig. 1).
PMCA with fully glycosylated human PrP ${ }^{C}$ substrates

Treatment by PMCA (single round, as in the entire study) of $\mathrm{PrP}^{\mathrm{D}}$ species associated with different subtypes of sCJD showed great variability in their propensity to amplify, depending on SCJD subtype and $129 \mathrm{M} / \mathrm{V}$ polymorphism of the $\operatorname{PrP}^{\mathrm{C}}$ substrate (Figs. 1a and 2; Tables 1 and 2). Using the $\operatorname{PrP}^{\mathrm{C}}-129 \mathrm{M}$ substrate, PK-resistant $\operatorname{PrP}^{\mathrm{D}}\left(\operatorname{resPrP}^{\mathrm{D}}\right)$ associated with SCJDMM1 and SCJDVV2 was amplified 3.19- and 9.64-fold, respectively, while the levels of sCJDVV1 and sCJDMM2 resPrP ${ }^{\mathrm{D}}$ exhibited a paradoxical decrease, up to 3-fold for sCJDMM2 (Figs. 1a and 2; Tables 1 and 2). With the $\operatorname{PrP}^{\mathrm{C}}-129 \mathrm{~V}$ substrate, $\operatorname{resPrP}^{\mathrm{D}}$ decreased by almost 4 times for SCJDMM2, remained virtually unchanged for SCJDMM1 and SCJDVV1, and increased 40-fold for sCJDVV2. This last amplification allowed the detectability of sCJDVV2 at up to $2.62 \times 10^{3}$ brain dilution, the highest amplification of all sCJD subtypes using fully glycosylated $\operatorname{PrP}^{\mathrm{C}}$ as substrate (Figs. 1a and 2; Tables 1 and 2). Much higher amplification was achieved, using the $\operatorname{PrP}^{\mathrm{C}}-129 \mathrm{M}$ substrate, for vCJD. In this case, resPrP ${ }^{\mathrm{D}}$ was detectable at up to $5 \times 10^{8}$ dilution, an amplification of $3.59 \times 10^{5}$-fold (Figs. $1 \mathrm{~b}$ and 2; Tables 1 and 2).

\section{PMCA with partially deglycosylated PrP ${ }^{C}$ substrate}

The use of partially deglycosylated $\operatorname{PrP}^{\mathrm{C}}$ substrates, obtained by PNGase F digestion (Supplementary Fig. 2), resulted in a significant increase of $\operatorname{resPrP}^{\mathrm{D}}$ PMCA amplification of all CJD seeds tested with the PrP-129 homologous substrate. This effect was particularly evident for SCJDMM2 and SCJDVV2 where, using the respective seed-substrate pairing, $\operatorname{resPr}^{\mathrm{D}}$ was detectable at up to $10^{6}$ brain dilution, resulting in a net amplification of $2.22 \times 10^{3}$ and 54.63-fold respectively (Figs. 1 and 2; Tables 1 and 2). In $\mathrm{vCJD}$ resPrP ${ }^{\mathrm{D}}$ amplification were unexpectedly high, reaching the detectability at $3.37 \times 10^{16}$ brain dilution with a net amplification of approximately 10 billion-fold over the amplification with the normally glycosylated $\mathrm{PrP}^{\mathrm{C}}$ $129 \mathrm{M}$ substrate (Figs. 1b and 2; Tables 1 and 2). Quantification of resPrP $\mathrm{P}^{\mathrm{D}}$ in $\mathrm{vCJD}$ seed showed a concentration of $24.9 \mu \mathrm{g} r \mathrm{resP}^{\mathrm{D}} / \mathrm{mg}$ brain. Estimating a weight of around $4.1 \times 10^{-20} \mathrm{~g}$ for a single vCJD-resPrP $\mathrm{P}^{\mathrm{D}}$ molecule (average of the 3 glycoforms), 6.1 resPrP $\mathrm{P}^{\mathrm{D}}$ molecules is expected to be present in $100 \mu \mathrm{l}$ (the volume used in PMCA analysis) of $10^{16}$-fold diluted brain (Supplementary Fig. 4).

\section{PMCA with unglycosylated PrPC substrate}

When PMCA was performed with the totally unglycosylated $\mathrm{PrP}^{\mathrm{C}}-129 \mathrm{M}$ substrate (MGlyKO) from the TgNN6h mice, $\operatorname{resPrP}^{\mathrm{D}}$ amplification was further increased for both 


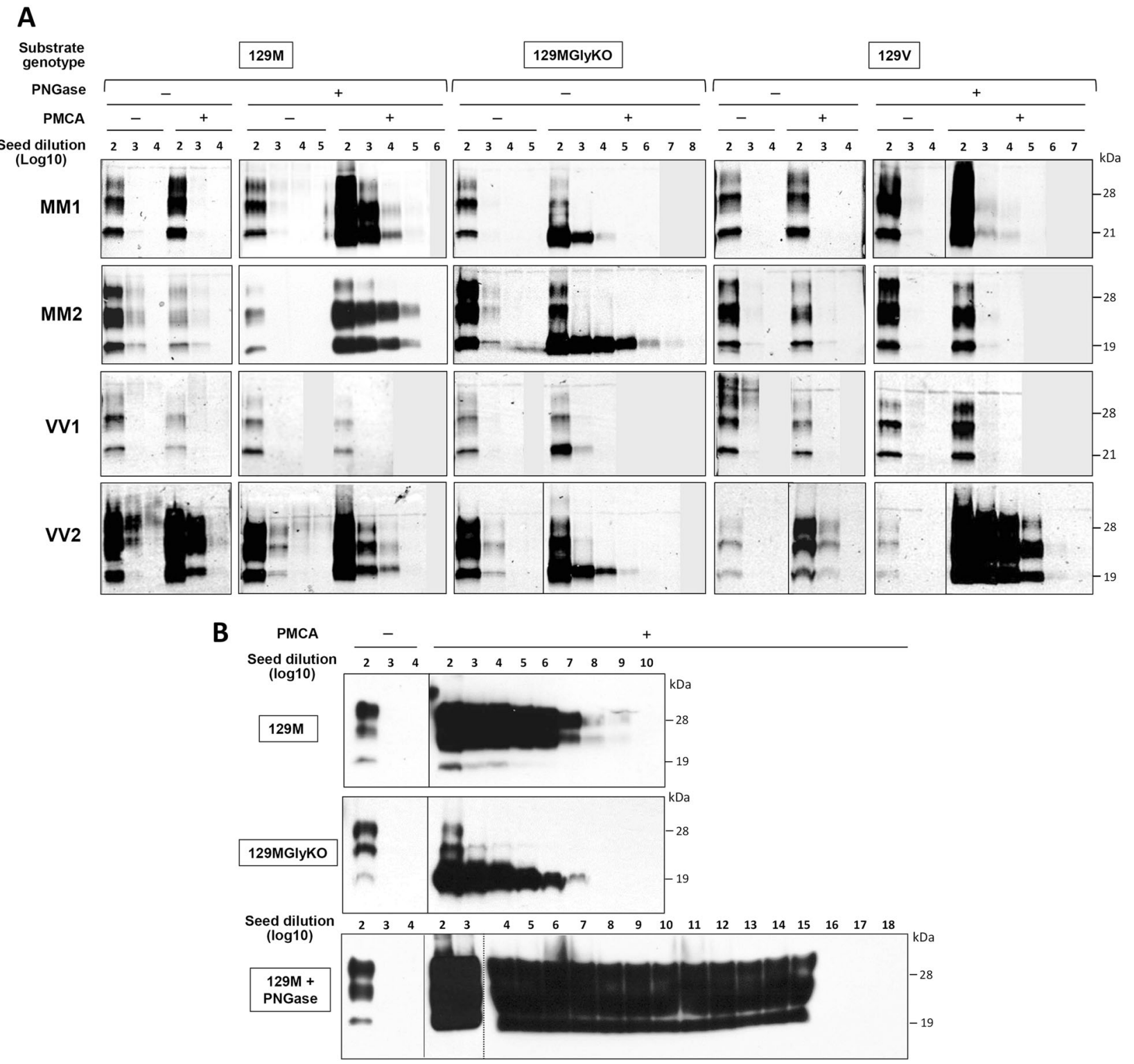

Fig. 1 Amplification of resPrP ${ }^{\mathrm{D}}$ from different sCJD subtypes and vCJD by PMCA with five distinct substrates. a Immunoblots of PKresistant disease-related prion protein $\left(\operatorname{resPr}^{\mathrm{D}}\right)$ from the indicated sCJD subtypes brain homogenates $(\mathrm{BH})$ that, used as seed, were submitted to limit dilution of carrier brain homogenates (seed dilution, expressed as $\log 10,2-8$ ) and were analyzed before and after PMCA treatment. PMCA was performed with five substrates: fully glycosylated PrP, 129M and 129V, (PNGase -); partially deglycosylated PrP,

sCJDMM1 and SCJDMM2 subtypes. The enhancement was marginal for sCJDMM1 (1.09-fold) but significant for sCJDMM2 (15.54-fold), achieving resPrP $\mathrm{P}^{\mathrm{D}}$ detectability at up to $5.5 \times 10^{7}$ brain dilutions (Figs. 1a and 2; Tables 1 and 2).

The lack of glycan-free human $\operatorname{PrP}^{\mathrm{C}}-129 \mathrm{~V}$ substrate prevented examination of its effect on $\operatorname{resPr}^{\mathrm{D}}$ amplification for SCJDVV1 and SCJDVV2. However, a distinct increase of amplification efficiency was also observed with the glycan-free $\mathrm{PrP}^{\mathrm{C}}-129 \mathrm{M}$ (TgNN6h) when compared with the
$129 \mathrm{M}$ and 129V (PNGase +); totally unglycosylated PrP (129MGlyKO). The concentration variability of $\mathrm{PrP}^{\mathrm{D}}$ in some PMCAuntreated samples is due to different preparations and/or different cases. Every panel shows samples run in a single gel; black lines refer to panel cropped to size. $\mathbf{b}$ vCJD; procedure as in (a) but with the three indicated substrates and $\log 10,2-18$. Lanes separated by the dotted line in the middle panel were run in two separate gels due to high number of samples

partially deglycosylated $\operatorname{PrP}^{\mathrm{C}}-129 \mathrm{M}$ substrate. For sCJDVV1 the increment was approximately 3.4-fold, but it is still only about a half of the amplification obtained with partially deglycosylated $\mathrm{PrP}^{\mathrm{C}}-129 \mathrm{~V}$ (Fig. 2 and Table 1). Nonetheless, the detection limit was paradoxically higher than that with partially deglycosylated $129 \mathrm{~V}$ (Fig. 1 and Table 2). sCJDVV2 also showed an amplification increase of 2.28-fold, but it is still 24 times lower than that obtained with partially deglycosylated $\operatorname{PrP}^{\mathrm{C}}-129 \mathrm{~V}$ substrate. (Figs. 1a 
A

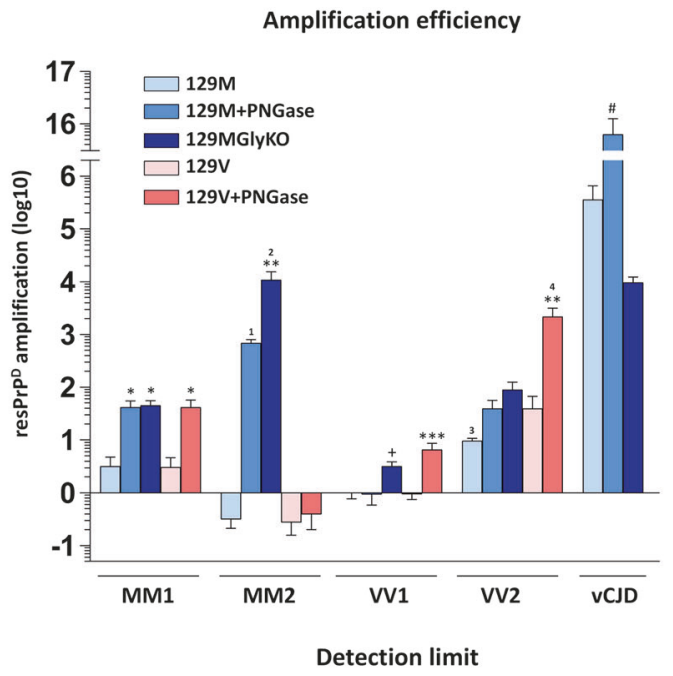

B

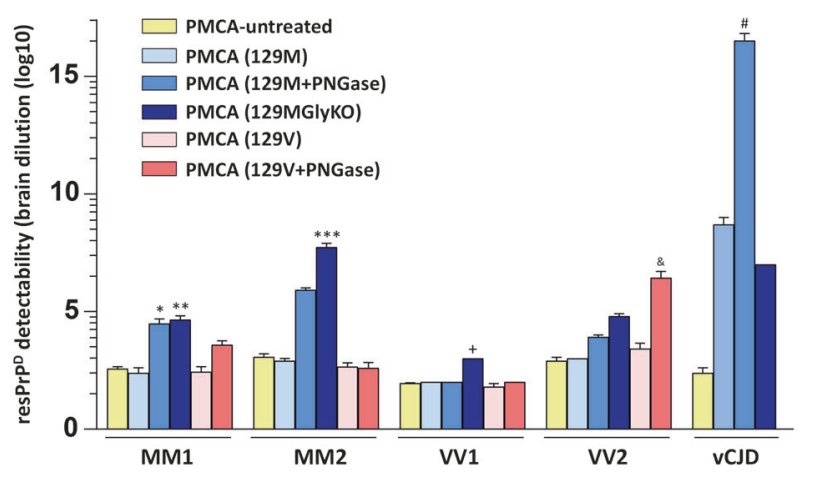

Fig. 2 Bar graph of amplification efficiency and limit detectability of resPrP $\mathrm{P}^{\mathrm{D}}$ from four SCJD subtypes and $\mathrm{VCJD}$ by PMCA using distinct substrates. The five substrates were: (1) fully glycosylated PrP denoted $129 \mathrm{M}$ and $129 \mathrm{~V}$; (2) partially deglycosylated PrP, $129 \mathrm{M}$ and $129 \mathrm{~V}$ denoted $129 \mathrm{M}+$ PNGase and $129 \mathrm{~V}+$ PNGase; (3) completely unglycosylated PrP denoted 129MGlyKO. Only 129M, 129M + PNGase, and 129MGlyKO were used for vCJD. Values are expressed as mean \pm SEM. At least a PMCA duplicate on 2 cases was performed in all sCJD subtypes, while a single case was tested in VCJD and MM2 with $129 \mathrm{~V}+\mathrm{PNGase}$ substrate. The number of PMCA experiments (4-8) performed for each group is specified in Tables 1 and 2. a Amplification efficiency. Statistical significance: $* p<0.0001$ vs PMCA-untreated (value 0) and $p<0.02$ vs $129 \mathrm{M}$ and $129 \mathrm{~V}$; $* * p<$ 0.0001 vs PMCA-untreated and every substrate; $* * * p<0.001$ vs PMCA-untreated and every substrate; ${ }^{+} p<0.05$ vs PMCA-untreated; ${ }^{\#} p<0.0001$ vs PMCA-untreated and every substrate of all tested CJD subtype; ${ }^{1} 129 \mathrm{M}+$ PNGase of MM2 is statistically different from that of MM1, MM2, and VV1, $p<0.0001 ;{ }^{2} 129$ MGlyKO of MM2 is statistically different from that of MM1, VV2, and VV1, $p<0.002$; ${ }^{3} 129 \mathrm{M}$ of VV2 is statistically different from that of MM1, $p<$ 0.005 and from that of MM2 and VV1, $p<0.002 ;{ }^{4} 129 \mathrm{~V}+$ PNGase of VV2 is statistically different from that of MM1 and MM2, $p<0.02$, and VV1, $p<0.005$. b Detection limit. Statistical significance: ${ }^{*} p<$ 0.02 vs PMCA-untreated; ** $p<0.02$ vs PMCA-untreated and every substrate, with the exception of $129 \mathrm{M}+$ PNGase; $* * * p<0.001$ vs PMCA-untreated and every substrate; ${ }^{+} p<0.0001$ vs PMCAuntreated and every substrate; ${ }^{\&} p<0.01$ vs PMCA-untreated and every substrate; ${ }^{\#} p<0.0001$ vs PMCA-untreated and every substrate of all tested CJD subtype. For description, see "Results"

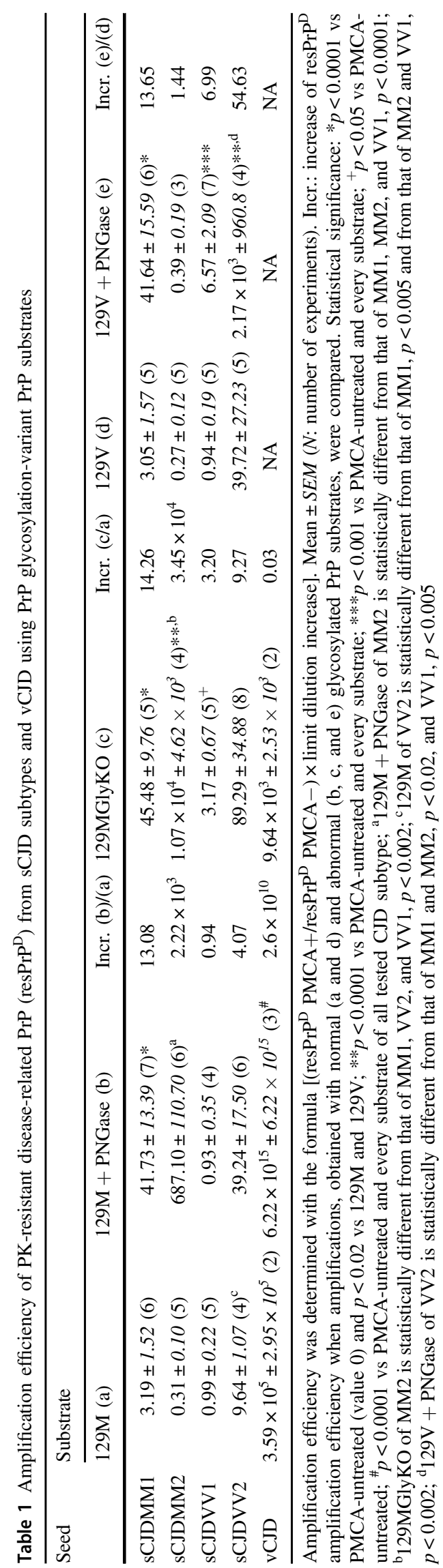




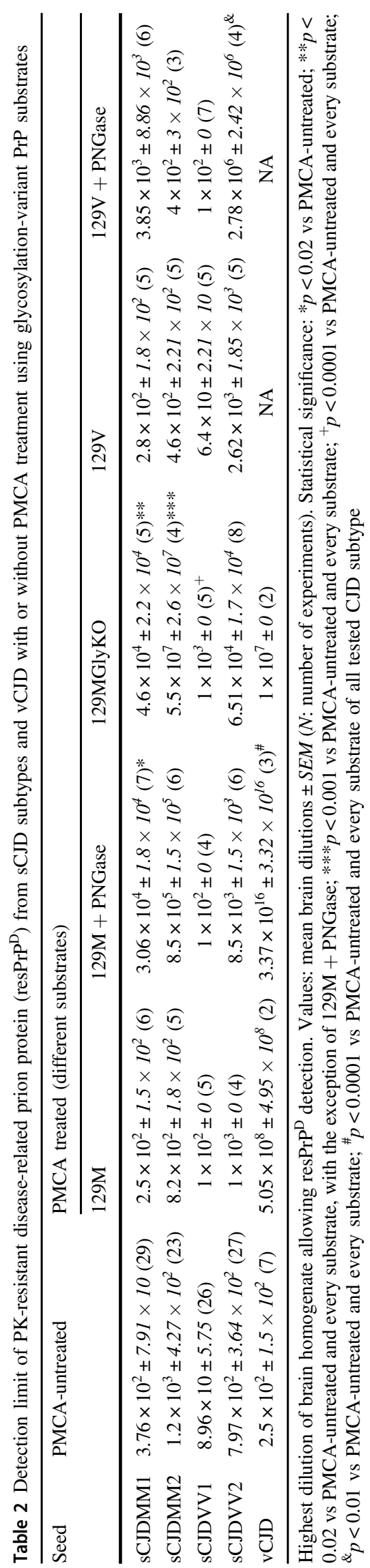

and 2; Tables 1 and 2). Unexpectedly, vCJD showed a major reduction of amplification vs that obtained with both partially glycosylated $\operatorname{PrP}^{\mathrm{C}}\left(6 \times 10^{11}\right.$-fold $)$ and totally glycosylated $\operatorname{PrP}^{\mathrm{C}}$ (37-fold) (Figs. 1b and 2; Tables 1 and 2).

No spontaneous resPrP has been detected, after PMCA, in any unseeded-substrate (Supplementary Fig. 3).

\section{Discussion}

Our findings show that the extent of glycosylation of the $\operatorname{PrP}^{\mathrm{C}}$, used as a substrate in PMCA, strongly impacts the amplification of resPrP $\mathrm{P}^{\mathrm{D}}$ from all sCJD subtypes tested and vCJD. Furthermore, diminished or total lack of $\operatorname{PrP}^{\mathrm{C}}$ glycosylation appears to strengthen the requirement for genotype matching at residue 129 between seed and substrate. For SCJD, we observed that the amplification inversely correlated to the degree of $\operatorname{PrP}^{\mathrm{C}}$ glycosylation, reaching the highest levels with glycan-free $\operatorname{PrP}^{\mathrm{C}}-129 \mathrm{M}$ in sCJDMM1 and SCJDMM2, and with partially deglycosylated $\operatorname{PrP}^{\mathrm{C}}$ $129 \mathrm{~V}$ (the only glycan variant available with $129 \mathrm{~V}$ genotype) for sCJDVV1 and sCJDVV2 subtypes.

At variance with this pattern, vCJD resPrP $\mathrm{P}^{\mathrm{D}}$ amplification, which is already very high with the fully glycosylated $\mathrm{PrP}^{\mathrm{C}}$ substrate, further increased by 10 logs with partially deglycosylated $\mathrm{PrP}^{\mathrm{C}}$ but decreased, when using the glycanfree $\operatorname{PrP}^{\mathrm{C}}$ substrate, to a level even lower than that achieved with the normally glycosylated substrate.

The observed effect of glycan-free $\operatorname{PrP}^{\mathrm{C}}-129 \mathrm{M}$ is probably underestimated in our study as the $\operatorname{PrP}^{\mathrm{C}}$ level in this $\mathrm{Tg}$ mouse line ( $\mathrm{TgNN} 6 \mathrm{~h})$ is only $25 \%$ of that in the $\mathrm{Tg}$ line expressing fully glycosylated $\operatorname{PrP}^{\mathrm{C}}-129 \mathrm{M}, \mathrm{Tg}(\mathrm{HuPrPM})$. A possible direct effect of the PrP mutation of this Tg line (TgNN6h) on the PMCA efficiency cannot also be ruled out.

The variability of resPrP $\mathrm{P}^{\mathrm{D}}$ concentration observed in some samples (different cases and/or different tissue sampling) from the same subtype rendered more difficult the analysis of statistically differences using the limit detection method. However, the use of the densitometry-based method (amplification efficiency), independent from the different $\operatorname{PrP}^{\mathrm{D}}$ starting concentrations, showed significant subtype-specific PMCA properties. In addition to the above discussed peculiar PMCA characteristics of vCJD, our findings include the highest amplification efficiency of MM2 with totally unglycosylated $129 \mathrm{M}$ vs all tested subtypes and partially deglycosylated $129 \mathrm{M}$ vs sCJD subtypes. Furthermore, VV2 showed the best amplification efficiency of all sCJD subtypes with fully glycosylated $129 \mathrm{M}$ and with the $129 \mathrm{~V}$ substrates.

Previous studies have shown that the presence or absence of glycans in mouse or hamster $\operatorname{PrP}^{\mathrm{C}}$ may positively or negatively affect the transmission [31,32] and amplification by PMCA of different prion strains [26-30, 33]. Those 
observations suggest an important strain-specific role of host $\operatorname{PrP}^{\mathrm{C}}$ glycans in $\mathrm{PrP}^{\mathrm{D}}$ replication and infectivity. Similarly, preliminary data on SCJD bioassays in mice expressing glycan-free human PrP-129M (TgNN6h) have shown prominent reduction of incubation time associated with increased severity of $\operatorname{PrP}^{\mathrm{D}}$-related histopathology after inoculation with sCJDMM2 but not of sCJDMM1 (Cracco et al., 90th annual meeting of American Association of Neuropathologists, 2014, and Kong et al., unpublished data).

The mechanism underpinning the observed effect of $\operatorname{PrP}^{\mathrm{C}}$ glycosylation in PMCA is not clear. It may lie in the stabilizing effect of glycans on the $\operatorname{PrP}^{\mathrm{C}}$ structure, making it more resistant to misfolding; or in the effect of the glycans steric hindrance on the strain-specific $\operatorname{PrP}^{\mathrm{C}}-\mathrm{PrP}^{\mathrm{D}}$ interaction, consequently facilitating or hindering the specific conversion. The markedly different effect observed in SCJD and VCJD would favor the second hypothesis, also considering the typically distinctive glycosylation ratios of these two forms of CJD-PrP ${ }^{\mathrm{D}}$. Previous studies on scrapie strains, described an important role of sialylated N-linked glycans on $\mathrm{PrP}^{\mathrm{C}}-\mathrm{PrP}^{\mathrm{D}}$ conversion, with significant increase of the $\operatorname{PrP}^{\mathrm{D}}$ replication rate by PMCA after substrate desialylation $[34,35]$. The authors attributed this effect to constraints generated by electrostatic repulsion between terminal sialic residues on $\mathrm{N}$-linked glycans. If and how the results obtained in our study with deglycosylated substrates are related to this effect remains to be determined.

The greatest increases in $\operatorname{resPrP}^{\mathrm{D}}$ amplification that we obtained for sCJDMM2 and SCJDVV2 in a single round of PMCA, using partially or fully-deglycosylated $\operatorname{PrP}^{\mathrm{C}}$ substrates, reached levels comparable to that obtained for vCJD amplified with a normal $\mathrm{PrP}^{\mathrm{C}}$ substrate (Table 2). Therefore, these PMCA conditions may allow for the detection and electrophoretic profile identification of $\operatorname{resPr}^{\mathrm{D}}$ in body fluids or easily accessible peripheral tissues from patients with sCJDMM2 and possibly sCJDVV2, especially if using the eventual Tg mice expressing glycan-free $\operatorname{PrP}^{\mathrm{C}}-129 \mathrm{~V}$ and after performing $\operatorname{PrP}^{\mathrm{D}}$ enrichment procedures of the body fluids [36]. Moreover, knowing the PrP 129 genotype of the patient, the specific different detection limit might be used to distinguish patients with SCJDMM2 or -VV2 from those with -MM1 and -VV1. Since the amplification here reported was obtained in a single round of PMCA (96 cycles), the use of serial rounds of PMCA that greatly increase the amplification efficiency [18], might allow the direct detection of resPrP ${ }^{\mathrm{D}}$ of sCJDMM1 and -VV1 as well. These two subtypes, together with sCJDMM2 and sCJDVV2, account for nearly $90 \%$ of all cases of sCJD [37].

The vCJD resPrP ${ }^{\mathrm{D}}$ detection in brain diluted $3.4 \times 10^{16}$ fold after a single round of PMCA with partially deglycosylated $\operatorname{PrP}^{\mathrm{C}}$, is far higher than that previously reported of around $10^{7}$ and $10^{11}$-fold obtained with classical or modified PMCA conditions, respectively [24, 25, 38]. Consequently, it is reasonable to speculate that the use of PMCA with partially deglycosylated $\operatorname{PrP}^{\mathrm{C}}$ would afford the detection of resPrP $P^{\mathrm{D}}$ in vCJD urine and blood, which have estimated resPrP ${ }^{\mathrm{D}}$ concentrations equivalent to $\mathrm{vCJD}$ brain diluted $10^{12}-10^{13}$ and $10^{9}$-fold, respectively $[24,38]$, in a single round of PMCA rather than the 3-4 rounds needed in the original method described by Soto and colleagues [24, 38].

Against this backdrop, PMCA with glycan variant $\mathrm{PrP}^{\mathrm{C}}$ substrates might provide the platform, when combined with PrP codon 129 genotyping, for a diagnostic test suitable to identify subtypes of CJD in the living patient.

Acknowledgements The authors thank the patient families and the NPDPSC technical and administrative personnel, in particular Mss. Janis Blevins, Katie Glisic, and Wei Chen for their invaluable assistance. This study was supported in part by Spitz Award "The Spitz Brain Health Innovation Fund" to SN, NIH grants 5P01AI106705, 5R01NS083687 and Charles S. Britton Fund to PG.

\section{Compliance with ethical standards}

Conflict of interest The authors declare that they have no conflict of interest.

Ethics approval The human samples were provided by NPDPSC. All procedures were performed under protocols approved by the Institutional Review Board of University Hospitals of Cleveland and as per regulations of the Declaration of Helsinki. All animal studies were carried out in accordance with the recommendations in the Guide for the Care and Use of Laboratory Animals of the National Institutes of Health under protocols \#2016-0051 approved by the Institutional Animal Care and Use Committee of the Case Western Reserve University.

Publisher's note: Springer Nature remains neutral with regard to jurisdictional claims in published maps and institutional affiliations.

\section{References}

1. Prusiner SB, Hsiao KK. Human prion diseases. Ann Neurol. 1994;35:385-95.

2. Parchi P, Giese A, Capellari S, et al. Classification of sporadic Creutzfeldt-Jakob disease based on molecular and phenotypic analysis of 300 subjects. Ann Neurol. 1999;46:224-33.

3. Gambetti P, Kong Q, Zou W, Parchi P, Chen SG. Sporadic and familial CJD: classification and characterisation. Br Med Bull. 2003;66:213-39.

4. Puoti G, Bizzi A, Forloni G, Safar JG, Tagliavini F, Gambetti P. Sporadic human prion diseases: molecular insights and diagnosis. Lancet Neurol. 2012;11:618-28.

5. Tee BL, Longoria Ibarrola EM, Geschwind MD. Prion diseases. Neurol Clin. 2018;36:865-97.

6. Gambetti P, Cali I, Notari S, Kong Q, Zou WQ, Surewicz WK. Molecular biology and pathology of prion strains in sporadic human prion diseases. Acta Neuropathol. 2011;121:79-90.

7. Aguzzi A, Lakkaraju AKK, Frontzek K. Toward therapy of human prion diseases. Annu Rev Pharmacol Toxicol. 2018;58:331-51.

8. Appleby BS, Connor A, Wang H. Therapeutic strategies for prion disease: a practical perspective. Curr Opin Pharmacol. 2018; 44:15-9. 
9. Franceschini A, Baiardi S, Hughson AG, et al. High diagnostic value of second generation CSF RT-QuIC across the wide spectrum of CJD prions. Sci Rep. 2017;7:10655.

10. Bongianni M, Orrù C, Groveman BR, et al. Diagnosis of human prion disease using real-time quaking-induced conversion testing of olfactory mucosa and cerebrospinal fluid samples. JAMA Neurol. 2017;74:155-62.

11. Orrú CD, Yuan J, Appleby BS, et al. Prion seeding activity and infectivity in skin samples from patients with sporadic Creutzfeldt-Jakob disease. Sci Transl Med. 2017;9:eaam7785.

12. Edgeworth JA, Farmer M, Sicilia A, et al. Detection of prion infection in variant Creutzfeldt-Jakob disease: a blood-based assay. Lancet. 2011;377:487-93.

13. Orrú CD, Caughey B. Prion seeded conversion and amplification assays. Top Curr Chem. 2011;305:121-33.

14. Luk C, Jones S, Thomas C, et al. Diagnosing sporadic Creutzfeldt-Jakob disease by the detection of abnormal prion protein in patient urine. JAMA Neurol. 2016;73:1454-60.

15. Zanusso G, Monaco S, Pocchiari M, Caughey B. Advanced tests for early and accurate diagnosis of Creutzfeldt-Jakob disease. Nat Rev Neurol. 2016;12:325-33.

16. Ritchie DL, Ironside JW. Neuropathology of human prion diseases. Prog Mol Biol Transl Sci. 2017;150:319-39.

17. Morales R, Duran-Aniotz C, Diaz-Espinoza R, Chamacho MV, Soto C. Protein misfolding cyclic amplification of infectious prions. Nat Protoc. 2012;7:1397-409.

18. Saá P, Castilla J, Soto C. Ultra-efficient replication of infectious prions by automated protein misfolding cyclic amplification. $\mathrm{J}$ Biol Chem. 2006;281:35245-52.

19. Chen B, Morales R, Barria MA, Soto C. Estimating prion concentration in fluids and tissues by quantitative PMCA. Nat Methods. 2010;7:519-20.

20. Jones M, Peden AH, Wight D, et al. Effects of human PrPSc type and PRNP genotype in an in-vitro conversion assay. Neuroreport. 2008;19:1783-6.

21. Haldiman T, Kim C, Cohen Y, et al. Co-existence of distinct prion types enables conformational evolution of human PrPSc by competitive selection. J Biol Chem. 2013;288:29846-61.

22. Xiao X, Yuan J, Qing L, et al. Comparative study of prions in iatrogenic and sporadic Creutzfeldt-Jakob Disease. J Clin Cell Immunol. 2014;5:240.

23. Ironside JW. Variant Creutzfeldt-Jakob disease: an update. Folia Neuropathol. 2012;50:50-6.

24. Moda F, Gambetti P, Notari S, et al. Prions in the urine of patients with variant Creutzfeldt-Jakob disease. N Engl J Med. 2014; 371:530-9.
25. Barria MA, Lee A, Green AJ, Knight R, Head MW. Rapid amplification of prions from variant Creutzfeldt-Jakob disease cerebrospinal fluid. J Pathol Clin Res. 2018;4:86-92.

26. Piro JR, Harris BT, Nishina K, et al. Prion protein glycosylation is not required for strain-specific neurotropism. $\mathrm{J}$ Virol. 2009;83:5321-8.

27. Makarava N, Kovacs GG, Savtchenko R, et al. A new mechanism for transmissible prion diseases. J Neurosci. 2012;32:7345-55.

28. Makarava N, Savtchenko R, Baskakov IV. Selective amplification of classical and atypical prions using modified protein misfolding cyclic amplification. J Biol Chem. 2013;288:33-41.

29. Katorcha E, Makarava N, Savtchenko R, D’Azzo A, Baskakov IV. Sialylation of prion protein controls the rate of prion amplification, the cross-species barrier, the ratio of PrPSc glycoform and prion infectivity. PLoS Pathog. 2014;10:e1004366.

30. Moudjou M, Chapuis J, Mekrouti M, et al. Glycoformindependent prion conversion by highly efficient, cell-based, protein misfolding cyclic amplification. Sci Rep. 2016;6:29116.

31. Wiseman FK, Cancellotti E, Piccardo P, et al. The glycosylation status of PrPC is a key factor in determining transmissible spongiform encephalopathy transmission between species. J Virol. 2015;89:4738-47.

32. Neuendorf E, Weber A, Saalmueller A, et al. Glycosylation deficiency at either one of the two glycan attachment sites of cellular prion protein preserves susceptibility to bovine spongiform encephalopathy and scrapie infections. J Biol Chem. 2004;279:53306-16.

33. Nishina KA, Deleault NR, Mahal SP, et al. The stoichiometry of host PrPC glycoforms modulates the efficiency of PrPSc formation in vitro. Biochemistry. 2006;45:14129-39.

34. Baskakov IV, Katorcha E, Makarava N. Prion strain-specific structure and pathology: a view from the perspective of glycobiology. Viruses. 2018;10:E723.

35. Katorcha E, Makarava N, Savtchenko R, Baskakov IV. Sialylation of the prion protein glycans controls prion replication rate and glycoform ratio. Sci Rep. 2015;5:16912.

36. Notari S, Qing L, Pocchiari M, et al. Assessing prion infectivity of human urine in sporadic Creutzfeldt-Jakob disease. Emerg Infect Dis. 2012;18:21-8.

37. Collins SJ, Sanchez-Juan P, Masters CL, et al. Determinants of diagnostic investigation sensitivities across the clinical spectrum of sporadic Creutzfeldt-Jakob disease. Brain 2006;129:2278-87.

38. Concha-Marambio L, Pritzkow S, Moda F, et al. Detection of prions in blood from patients with variant Creutzfeldt-Jakob disease. Sci Transl Med. 2016;8:370ra183. 